Adolescents' family and peer social systems influence each other in many ways. Considering these systems in light of how ethnicity has been conceptualized by researchers, we offer a set of general principles to guide future research on ethnic or cultural influences on family-peer linkages in adolescence.

\title{
The Cultural Context of Family-Peer Linkages in Adolescence
}

\author{
B. Bradford Brown, Nina S. Mounts
}

By nature, humans are social beings, dependent on relationships with others for their survival and well-being. Family relations are a core component of human experience, but in most societies individuals venture beyond the family crucible sometime during childhood or adolescence to form meaningful relationships with peers. As a result, family-peer linkages are a crucial aspect of human development. There is extensive scholarship about these linkages during childhood, but surprisingly little work on connections between family and peer relationships during adolescence. Moreover, only recently have scholars begun to consider the degree to which and how family-peer linkages are culturally embedded and affected by social and ethnic backgrounds. This work heralds a new era in research on connections between adolescents' peer and family worlds. Such research requires awareness of the limitations of previous scholarship as well as understanding of the many ways in which family and peer relationships may intersect in adolescence. Likewise, researchers must be attentive to the variety of ways in which ethnicity or culture has been conceptualized or operationalized in social scientific research. In this chapter we consider these issues and then present a set of general principles that can guide future investigations of family-peer linkages in adolescence.

\section{(\$ILEY




\section{Previous Research on Family-Peer Linkages}

Families and peers constitute two of the three most significant social contexts for American youth (the third being educational settings) (Brown and Larson, 2002). They are responsible for young people's social development and provide most of a young person's significant social relationships. By adolescence, they are primary sources of emotional and instrumental support and account for the lion's share of socialization into cultural norms and values. Healthy family and peer relationships are associated with positive psychological and social outcomes (Collins and Laursen, 2004; SavinWilliams and Berndt, 1990). In most cases, family and peer systems complement each other, but there can be times, especially at the onset of adolescence, when they compete for the young person's allegiance and attention (Savin-Williams and Berndt, 1990). The central role that family and peers play in youth development underscores the importance of understanding the nature and consequences of family-peer linkages.

The study of these linkages has been pursued through several theoretical lenses, but most notably from the perspectives of attachment theory and some form of socialization theory. The former considers how parent-child bonds form the emotional core of human connections that young people extend to successive relationships with peers (Bowlby, 1989). The latter views adult kin (primarily parents) as agents of instruction and guidance, helping to hone young people's social skills and guiding them to healthy relationships with agemates (Parke and Bhavnagri, 1989).

Studies emanating from these theoretical roots have been remarkably informative, but also limited in several ways. By and large they have been confined to mainstream youth in a society (for example, white, middle-class youth in North America) and have concentrated on toddlerhood and early childhood. Rarely have data been drawn from more than one of the three major constituents (youth, family members, peers). Investigators have focused on parents to the exclusion of other family members, and on friends rather than the broader array of peer relationships. Moreover, investigators concentrate on how family adults influence children in the formation and operation of their peer relationships, but they rarely consider other patterns of influence, such as how peers affect family relationships or how children broker interactions between family members and peers. Little attention has been given to bidirectional or multidirectional models of influence.

One conspicuous shortcoming of previous research is inattention to cultural or ethnic background. Norms and interpersonal processes that characterize family and peer relations vary widely across cultures, especially as young people move beyond childhood (Edwards, 1992). In some societies or cultural groups, young people are afforded little time or opportunity to engage in relationships with agemates (Booth, 2002), whereas in others parental authority and family interaction are expected to diminish in the face of expanding interaction with peers (Arnett, 2002; Youniss and 
Smollar, 1985). Romantic relationships are carefully scripted and controlled by parents in some ethnic communities, whereas in others the details of romantic relationships are routinely hidden from parents (Simon, Bouchey, and Furman, 2000). Such fundamental differences in the nature of family and peer worlds undermine the generalizability of features of family-peer linkages. Even the common practice of generalizing findings within a given ethnic group is problematic because of significant variability in norms and interpersonal processes across families within one such group (Updegraff, Killoren, and Thayer, in Chapter Four of this volume).

Ethnicity seems to frame the nature of adolescents' social relationships within and between the family and peer group. The challenge for researchers is to identify the specific facets of ethnic or cultural background that influence these relationships and incorporate them into research on family-peer linkages. A major issue in this regard is how to conceptualize culture or ethnicity.

\section{Common Perspectives on Ethnic and Cultural Influences}

There is little consensus among scholars on how to define or operationalize ethnicity. In fact, in previous research on adolescents in multicultural societies, ethnicity has been conceptualized in at least four ways.

Social Position. In some societies, one of the most distinctive features of ethnic groups is the different social positions that they occupy. Members of one group may enjoy high prestige or socioeconomic position, whereas other groups are relegated to moderate- or low-status positions. If prestige or status affects economic opportunities and access to positions of power or authority, it makes sense to interpret ethnic differences in terms of social position. Studies of ethnic and racial prejudice or discrimination fall into this category, as do studies examining how immigrant and other ethnic groups are situated in the socioeconomic structure of the society.

A classic example of this work is research on friendship patterns among adolescents following legislation to desegregate schools in the United States. Social contact theory proposed that individuals would engage in mutual relationships such as friendship only if they encountered each other in social circumstances of equality (Aronson, 1978). American schools that were technically desegregated (enrolling students of different races) were often resegregated by placing members of one group almost exclusively in lower academic tracks and members of another group in more advanced classes, or by restricting access to certain extracurricular activities to members of one group. In this way, schools or communities met the letter of the law while maintaining discriminatory practices that perpetuated socioeconomic differences among racial or ethnic groups. Schofield (1982) found that school desegregation did little to forge closer social relations between African American and European American young people in some communities because 
the two groups had little contact with each other in classes or after-school activities. By contrast, Peshkin (1991) described a California community in which young people mixed freely across ethnic lines, partly because there were not clear social or academic divisions among the groups.

Cultural Norms. Although adults in the community that Peshkin observed were comfortable with their adolescents forming friendships across ethnic lines, many actively resisted interethnic romantic relationships. This finding is best explained by a second perspective on ethnicity, one emphasizing norms, values, customs, or lifestyles that characterize a given culture or differentiate it from other groups. Despite their ease in associating with other groups, many adults in Peshkin's community staunchly maintained cultural traditions and expected their offspring to follow suit. They regarded within-group marriage as essential to retention of cultural traditions and values, thus viewing interethnic dating as dangerous and unacceptable.

Characterizing ethnic groups by their beliefs and practices is quite common in studies of adolescents (see Way, Greene, and Mukherjee, in Chapter Three of this volume). In some cases, scholars will point to key values that organize relationships and interaction patterns in specific ethnic groups, such as familismo and machismo in Latino groups (Harwood and others, 2002), or family honor in Southeast Asian communities (Trueba, Jacobs, and Kirton, 1990). In other cases, they will examine the consequences of group differences regarding a specific principle, such as respect for elders (Zhou and Kim, 1990). Usually, investigators acknowledge the variability apparent among members of a given cultural or ethnic group in allegiance to the norms, values, or customs that are used to characterize it.

Interpersonal Processes. A third common approach to ethnicity is to focus on characteristics or dynamics of key social relationships, especially in the family. The idea is that a certain pattern of relationships or a certain interpersonal style dominates social interactions among members of a given ethnic group, accounting for some of the commonalities observed within the group (or differences between groups) in individual development and behavior. For example, a central organizing feature of family relations in some cultures is deference to parental authority, whereas in other cultures there is a developmental shift in adolescence and adulthood to more egalitarian relationships. Smetana $(1988,2000)$ has demonstrated how African American and European American adolescents try to restrict the domains in which parents can legitimately set rules by claiming more personal jurisdiction over various activities. Autonomy is advanced when parents accede to adolescents' demands for more personal control of their lives (Collins and others, 1997). In other cultures, however, adolescents' efforts to delimit parental authority can disrupt parent-child relations and family dynamics (Brown, Bakken, Nguyen, and Von Bank, in Chapter Five of this volume; Xiong, Detzner, and Cleveland, 2004-05). 
These issues are central to the distinction between individualistic and collectivistic cultures (Killen and Wainryb, 2000). Extensive relations with nonkin peers are more problematic in collectivistic cultures because they can interfere with young people's obligations to the family and their allegiance to adult authority. On the other hand, a sense of integration with broad kin networks can enhance contact with relatives who are close in age, creating a natural linkage between family and peers.

Social Organization. Finally, ethnicity is often examined in terms of how the family or other social units within the culture are structured or organized. Different patterns of activity and relationships occur in cultures that emphasize the nuclear rather than the extended family as the common organizational unit. Extended families offer a wider array of resources and opportunities for social interaction to parents and adolescents. This may encourage youth to focus most of their peer relationships on siblings and cousins, who are more easily "tracked" by parents than nonrelated peers. The organizationally based ethnic difference is often manifested in the value placed on kin and nonkin relationships. Compared to nuclear-oriented European American families, parents and youth in extended-family ethnic groups are more likely to express reservations about trusting or investing time in nonkin peers (see Way, Greene, and Mukherjee, in Chapter Three of this volume; Updegraff, Killoren, and Thayer, in Chapter Four of this volume).

Variations also can be traced to authority structure: whether families are matriarchal or patriarchal or feature more shared authority between husband and wife (Seginer, Shoyer, Hossessi, and Tannous, in Chapter Six of this volume). In multicultural societies, some groups may be inclined to congregate in particular cities or neighborhoods, whereas others disperse throughout a community. Such inclinations affect the pool of peers from which an adolescent can develop friendships or romantic relationships (Wade and Okesola, 2002).

Implications for the Study of Family-Peer Linkages. Although distinctive, these four perspectives on ethnicity or culture are interrelated. Social organization is shaped and reinforced by cultural norms and values. Socioeconomic position and encounters with discrimination can influence the values and lifestyles that particular groups adopt. Interpersonal processes, especially the nature of parent-child relationships, differ in matriarchal, patriarchal, and egalitarian social groups. Thus no single perspective is comprehensive or necessarily superior to the others. All of these aspects of ethnicity are likely to shape the nature of family-peer linkages, often fundamentally. They can affect the degree to which adolescents are exposed to peers and the types of peers available for relationships. They should influence specific features of peer and family relationships-level of intimacy, involvement, and support, for example-as well as how family and peer networks are interrelated. One perspective, however, may be more salient in certain aspects of family-peer linkages than in others. For exam- 
ple, a family's social position should have a strong impact on the types of peers to which an adolescent is exposed, whereas interpersonal processes may play a stronger role in the types of conversations the child has with parents about friends.

The chapters in this volume illustrate the importance of applying a variety of perspectives on ethnicity to analyses of family-peer linkages, sometimes coordinating multiple perspectives in attending to a specific issue of linkage. Seginer and her colleagues consider ethnic differences in both cultural norms and interpersonal processes in examining the similarities between sibling and nonkin peer relationships. Cultural norms and values as well as social position contribute to ethnic differences in the goals and concerns that parents in Mounts and Kim's study express about their child's peer relations. Updegraff and her coauthors include both social position and cultural norms in their effort to identify subgroups within one ethnic community. A major challenge for researchers is to identify and coordinate the multiple facets of ethnic or cultural background that can affect family-peer linkages.

\section{Types of Family-Peer Linkages in Adolescence}

Just as there are multiple perspectives on or dimensions of ethnicity in multicultural societies, there are also several ways in which adolescents' family and peer worlds intersect. We organize this work into four primary modes. The first two focus on family influences on peer relations, reflecting the preponderance of research on family-peer linkages in childhood. The other two consider peer influences on family relations or peer compensation for the absence of adequate family ties, emphasizing the bidirectional nature of linkages between the two social contexts. In describing these four modes of linkage, we are especially attentive to issues of ethnicity and culture, but we remain more speculative than definitive because of the dearth of appropriate research.

Direct Influence of Family on Peer Relationships. Some researchers have concentrated on what we regard as direct influence of family members, especially parents or guardians, on adolescents' peer relations. Included in this category are activities of parents, guardians, siblings, and extended family members that, whether intentionally or unintentionally, have a direct and unmediated impact on the nature of adolescents' interactions or relationships with peers (see Mounts, 2002; Mounts and Kim, in Chapter Two of this volume). For example, parents or guardians may "monitor" children's peer interactions, by observing them directly or soliciting information about them from their children, and then using this information to set parameters for peer interactions. Parents can establish a curfew or require that all activities with peers be preapproved. They may offer explicit advice about how to ask someone out, confront a bully, or respond to something hurtful that a friend or acquaintance did. 
Direct influence can extend further to such activities as limiting a child's peer interactions to associates whom the family has met, prohibiting dating until the child reaches a certain age, "engineering" friendships with specific peers (Vernberg, Beery, Ewell, and Abwender, 1993), or arranging a marriage for the child (Medora, 2003). Of course, by failing to engage in any of these behaviors, the family can also have a substantial impact on young people's peer relations. Intentionally or inadvertently neglecting to set any curfew for a child or never checking on what a child is doing with peers can have as much of an effect on peer relations as being highly vigilant and restrictive.

Within a primarily European American sample, Mounts (2001) found that some parental oversight facilitates healthier relationships with peers, but too extensive involvement undermines both the child's peer relationships and the quality of the parent-child bond. In cultures that emphasize family loyalty and obedience to parents, however, more extensive parental oversight or involvement does not seem to be problematic for the adolescent (Phinney, Kim-Jo, Osorio, and Vilhjalmsdottir, 2005).

Most studies portray direct family influences in unidirectional terms, such that the actions of parents affect children's behaviors but are not affected by them. In reality, however, adolescents usually play an instrumental role in this process. As young people grow older, parents' opportunities for direct oversight diminish, requiring them to base their actions primarily on information about peers that is provided by the child (Kerr and Stattin, 2000). Young people employ a variety of strategies to censor information about peers or restrict parents' access to it (Brown, Bakken, Nguyen, and Von Bank, in Chapter Five of this volume; Jensen, Arnett, Feldman, and Cauffman, 2004), thereby affecting the level of control that parents wield. By telling her parents that she is going to the public library to study, when in reality she is going over to her boyfriend's house, an adolescent can avoid having parents refuse her request to see the boy, or she can obviate a parental dictum against romantic relationships.

Too little attention has been paid to the direct effects of family members other than parents, especially siblings and cousins. These relatives may broker romantic relationships or impede interactions with a romantic partner. They may ward off a bully or tease and demean a child in front of other peers. They may offer an alibi for or "rat out" a child who engages in peer interactions that parents would not normally permit. They may be such a strong source of activities and support that the adolescent feels little need to venture beyond the family for peer interaction and relationships.

Indirect Influence of Family on Peer Relationships. Behaviors of parents and guardians, siblings, and other kin can influence adolescents' peer interactions and relationships more indirectly (Mize, Russell, and Pettit, 1998; Parke and O'Neil, 1999). For example, parenting styles or parenting practices may foster particular interests or social characteristics that 
direct a child to affiliate with certain peers or peer groups rather than others (Brown, Lamborn, Mounts, and Steinberg, 1993). Parents' efforts (or lack of them) to foster general social skills in their child can affect a young person's capacity to make and maintain friendships, thereby influencing who is befriended and how long the relationship lasts. In each case, the effects of family members' actions on adolescent peer relations are mediated by some other factor: the child's personal characteristics, the types of peers available for relationships, and so on.

The most widely researched example of indirect family influences comes from the attachment literature. A major premise of this theory is that features of the child's relationship with caregivers early in life become the blueprint for all subsequent close relationships, including those with peers. The "working model" that young people retain from their early attachments to family adults influences their interest in establishing close ties to peers and specific features of those ties. This idea has been examined most frequently with reference to late-adolescent or young-adult romantic relationships (for example, Hazan and Shaver, 1987); less attention has been paid to its relevance to peer affiliations earlier in adolescence (but see Freeman and Brown, 2001).

Again, research must be extended to a broader array of family relationships, especially siblings. Sibling relationships may be a more meaningful blueprint for nonkin peer affiliations than parent-child bonds because they better reflect the more egalitarian nature of peer ties. Beyond this, parents' experiences with an older brother or sister may guide their approach or response to peer issues arising from the next child to reach adolescence.

As with direct influences, the indirect influence process is likely to be bidirectional, such that actions or characteristics of the child affect family members' behavior rather than just being (indirectly) affected by the family. A parent's decision to move or join a specific community organization, for example, may be prompted by assessment of the child's social needs. Thus, specifying the nature of indirect influences becomes especially challenging.

Peer Influence on the Family. Researchers have paid little attention to a third mode of linkage, namely, how peers or peer relationships influence family relationships and family dynamics. This may be a vestige of previous work on family-peer linkages in childhood because investigators would not expect young children or childhood peer interactions to have a profound effect on the family. By adolescence, however, peer relationships have grown more extensive, stabler, and more salient to young people (Savin-Williams and Berndt, 1990), enhancing their capacity to serve as influence agents. The majority of research on peer influence that incorporates family variables has treated family and peers as independent influence agents and focused attention on the consequences of each source of influence on the adolescent's behavior or well-being. Classic studies of parentpeer cross-pressures concluded that peers and parents have distinctive 
domains of influence, such that adolescents are more attentive to peers' advice on some issues and more attentive to parental opinions on other matters (Brittain, 1963; Larson, 1972).

Looking more directly at peer influence on family relations (rather than adolescents' behavior), one finds some evidence among American adolescents that peers are more likely to affirm than undermine parental authority and family interaction. Most of the teenagers that Clasen and Brown (1985) surveyed perceived more peer pressure to get along well with the family and accede to parental expectations and authority than to oppose these activities, although the strength of such pressures was weaker in older age groups.

Peers may also have a substantial impact on parenting behavior. TiltonWeaver and Galambos (2003) found that parents used peer management behaviors infrequently, most often when they sensed that peers were leading their child into misbehavior or threatening the child's safety and well-being. Other investigators have argued that a dangerous peer environment in urban, economically disadvantaged neighborhoods (gang activity, high rate of pregnancy, delinquent behavior among youth) accounts for the inclination of parents in such neighborhoods to adopt more restrictive, authoritarian parenting practices (Furstenberg, Cook, Eccles, and Elder, 1999). In other words, the ostensibly direct influence of parents on peer relations manifested in parental monitoring or rule making may often actually be parental reactions to peer behavior (or, at least, parental perceptions of such behavior).

The families of adults with whom parents socialize, whether kith or kin, may be the source of children's friendships, especially in childhood, because young people have considerable exposure to the offspring of these adults. By adolescence, however, the tables can turn, with parents of an adolescent's friends forming an important part of the parents' social circle. In middleclass, European American culture, young people who coalesce into a friendship circle tend to draw their parents together on the basis of the adults' desire to "check out" the characteristics of peers with whom their child is spending time, and the adults' need to check up on peer activities (such as making sure that a friend's parent is supervising an activity that one's child wants to attend). It becomes expedient for adults to form their social lives around the other families whom they frequently encounter in their children's activities (Fletcher, Newsome, and Nickerson, 2001; Lareau, 2003).

In some circumstances, peers may also serve as an inspiration, of sorts, for adolescents to attempt to change the nature of their relationships with parents or family members. Immigrant youth, especially, may be exposed through interaction with host culture peers to new forms of family relationships, which they then attempt to adapt to their own family circumstances. These efforts can strain parent-child relations if immigrant parents want to retain more traditional forms of family interaction (Deeds, Stewart, Bond, and Westrick, 1998). One response, of course, is for parents to place 
restrictions on their child's interactions with peers in order to undermine peer influences on the family. This illustrates the often complex, bidirectional, dynamic nature of family-peer linkages in adolescence.

Conflation of Contexts. Finally, family-peer linkages occur when relationships in one context operate as if they were in the other. The most common example is when nonkin peers are accorded the status of blood relatives, when friends are referred to and treated as cousins or siblings. A long-standing practice within the African American community (Chatters, Taylor, and Jayakody, 1994), this highlights the importance of family ties within this ethnic group. Because many minority youth and parents put less trust and faith in friendships than is typical of European Americans (see Way, Greene, and Mukherjee, in Chapter Three of this volume), naming someone as a cousin is a significant event. It elevates the relationship to that of an enduring, reliable blood tie, according the friend far more credibility and status among an adolescent's actual kin than the person would normally enjoy. The significance of such labeling and the circumstances that prompt it are not well understood; nor is there much evidence about the frequency and meaning of the practice in other ethnic groups.

Another instance of conflating context is when individuals in one context assume the role or responsibilities of relationships in the other. A wellknown example in the United States is when gang members become the equivalent of a family for young people. The authority structure of gangs, along with the age range of members, allows some older and more powerful gang members to act much like parents to younger members, and individuals occupying the same status position within the gang may mimic sibling relationships. Teens in dysfunctional families may find this feature of gangs particularly appealing, but the deviant aspects of gang activity can color the nature of within-gang relationships and call into question how closely they actually mimic family connections or even true friendships.

Occasionally, a parent will claim to be an adolescent child's best friend, or the child will name a parent as his or her best friend. Without some effort, it is difficult to determine whether such a comment is made in earnest or is hyperbole intended to underscore the sense of closeness and relative equality that the parent or adolescent feels within the relationship at this life stage. When adults adopt a more indulgent or laissez-faire parenting style, or when they engage in activities similar to those of their children, such as dating, it may appear as if they are abdicating the parental role in favor of a more peerlike relationship with their children. There is little scientific research, however, examining either the frequency of this event or the consequences for adolescent social and psychological development.

Intersection of Linkages. The wide variety of linkages that can occur between adolescents' peer and family worlds helps to explain the complex negotiations that often occur between parent and child about peer issues, 
as well as the challenges that adolescents face in navigating peer relations compatibly with family norms and parental expectations. These processes are further complicated by the fact that various modes of family-peer linkage operate simultaneously. At the same time parents try to define the rules governing their child's selection of peer associates and interactions with friends, adolescents' calendar of activities may reshape the parents' social circle and thereby the adults whom parents hope will support their rules for the child's engagement with peers. These forces may interact in distinctive ways according to the ethnic or cultural group, and when adolescent peer relationships extend across ethnic groups, additional issues arise.

All this makes for an exciting but complex field of inquiry that has not yet been thoroughly conceptualized, let alone researched. It may be too early to advance a comprehensive conceptual framework for future work in this area, but it is possible at this point to articulate a set of basic principles that can guide investigators' efforts.

\section{Guiding Principles for Future Research}

As researchers continue to explore the intersections of adolescents' family and peer worlds, it appears as if the field has grown beyond the two major theoretical approaches (attachment and socialization theories) that dominated earlier work. This is not to discount the powerful insights emanating from work based on these theories, but merely to suggest that a wider conceptual lens may be useful. In searching for theories or conceptual schemes to guide their work, the researcher should keep a number of principles in mind.

1. Family-peer linkages are shaped by the family's ethnic or racial background. Family authority structures, cultural norms and values, family position within the broader social structure, expectations for the timing and content of specific peer relationships, and interpersonal processes that are typical of peer and family interactions all affect the connections that are likely to be observed between adolescents' families and peers. All of these factors seem to vary among ethnic groups. This does not mean that every study must involve multiple ethnic or cultural groups in order to capture variability on these dimensions (see, for instance, Updegraff, Killoren, and Thayer, in Chapter Four of this volume). Rather, it underscores the need for investigators to be mindful of how the family-peer linkages on which their study concentrates are embedded within an ethnic and cultural context.

2. Family-peer linkages are shaped by the broader community context in which they occur. In addition to the child's own ethnic and cultural context, investigators must consider other such contexts in which children or families are engaged and how family-peer linkages connect multiple ethnic and cultural groups. Family-peer linkages in a multicultural context 
are complicated by the relative position of cultural or ethnic groups within that context, the nature of interaction patterns between groups, and the vested interests of adults and youth to have adolescents forge peer relationships across cultures as opposed to remaining within their own group.

3. Family-peer linkages are bidirectional. Especially in adolescence, peers can influence family dynamics and parent-child relationships, just as family relationships and dynamics can influence adolescent-peer interactions. Even in groups that feature strong, unilateral authority structures (favoring adult caretakers) in families, the increased mobility of adolescents allows them some control over adults' knowledge about their peer relations, which can be used to exercise influence in family negotiations about peer interactions (Brown, Bakken, Nguyen, Von Bank, in Chapter Five of this volume). Studies that are mindful of these bidirectional processes will be more insightful than research based on unidirectional models.

4. Family-peer linkages are organic and developmental. They continue to evolve, often predictably, across the course of adolescence, as a function of both the child's maturation and the accumulation of experiences between family members and peers. Cultural mandates such as expectations for increasing autonomy or a child's need to assume an increasing level of responsibility within the family can drive the sort of developmental changes that are observed in family-peer linkages.

5. Gender is a particularly significant factor in family-peer linkages. Although we have said little about gender, we appreciate its central role in many of the processes that we have mentioned. Gender roles and expectations regarding family activities and peer interactions vary across cultures and ethnic groups (Rogoff, 2003). So do the activity level and expectations of involvement for fathers and mothers (or other male or female adult guardians) in adolescent peer relations. Gender pairing (mother-son versus mother-daughter, for example, or the influence of an older sibling of the other sex) is also an important issue to consider.

6. Family influences are the result of both direct (proximal) and indirect (distal) family processes. Although there is some merit in focusing on just one level of influence, investigators ultimately need to understand how direct and indirect influences work together to affect and be affected by adolescent-peer relationships and behaviors.

\section{Moving Forward}

The emerging research on family-peer linkages in adolescence bears witness to the intriguing transformations that characterize these linkages across this stage of the life cycle. The resulting dynamics among an individual, peers, and family members require more bidirectional, multilevel models that are sensitive to contextual factors, especially culture and ethnicity. The work presented in this volume exemplifies the variety of approaches available to incorporate ethnicity into research designs concerning family-peer linkages. 
Contributors to the volume deftly illustrate many of the principles we articulate in this chapter to guide future research in the field.

The volume is intended to be illustrative and provocative, rather than comprehensive and definitive. The challenge that contributors present to scholars is to become more sensitive to the cultural context in which family and peer worlds intersect during adolescence.

\section{References}

Arnett, J. J. "Adolescence in Western Countries in the Twenty-First Century: Vast Opportunities-for All?" In B. B. Brown, R. W. Larson, and T. S. Saraswathi (eds.), The World's Youth. New York: Cambridge University Press, 2002.

Aronson, E. The Jigsaw Classroom. Beverly Hills, Calif.: Sage, 1978.

Booth, M. "Arab Adolescents Facing the Future: Enduring Ideals and Pressures to Change." In B. B. Brown, R. W. Larson, and T. S. Saraswathi (eds.), The World's Youth. New York: Cambridge University Press, 2002.

Bowlby, J. Secure Attachment. New York: Basic Books, 1989.

Brittain, C. V. "Adolescent Choices and Parent-Peer Cross-Pressures." American Sociological Review, 1963, 28, 385-391.

Brown, B. B., Lamborn, S. L., Mounts, N. S., and Steinberg, L. "Parenting Practices and Peer Group Affiliation in Adolescence." Child Development, 1993, 64, 467-482.

Brown, B. B., and Larson, R. W. "The Kaleidoscope of Adolescence." In B. B Brown, R. W. Larson, and T. S. Saraswathi (eds.), The World's Youth. New York: Cambridge University Press, 2002.

Chatters, L. M., Taylor, R. J., and Jayakody, R. "Fictive Kinship Relations in Black Extended Families." Journal of Comparative Family Studies, 1994, 25(3), 297-312.

Clasen, D. R., and Brown, B. B. "The Multidimensionality of Peer Pressure in Adolescence." Journal of Youth and Adolescence, 1985, 14, 451-468.

Collins, W. A., and Laursen, B. "Parent-Adolescent Relationships and Influences." In R. M. Lerner and L. Steinberg (eds.), Handbook of Adolescent Psychology. (2nd ed.) Hoboken, N.J.: Wiley, 2004.

Collins, W. A., and others. "Conflict Processes and Transitions in Parent and Peer Relationships: Implications for Autonomy and Regulation." Journal of Adolescent Research, 1997, 12, 178.

Deeds, O., Stewart, S. M., Bond, M. H., and Westrick, J. "Adolescents Between Cultures: Values and Autonomy Expectations in an International School Setting." School Psychology International, 1998, 19, 61-78.

Edwards, C. P. "Cross-Cultural Perspectives on Family-Peer Relations." In R. D. Parke and G. W. Ladd (eds.), Family-Peer Relationships: Modes of Linkage. Hillsdale, N.J.: Erlbaum, 1992.

Fletcher, A. C., Newsome, D., and Nickerson, P. "Social Network Closure and Child Adjustment." Merrill-Palmer Quarterly, 2001, 47, 500-529.

Freeman, H., and Brown, B. B. "Primary Attachment to Parents and Peers During Adolescence: Differences by Attachment Style." Journal of Youth and Adolescence, 2001, 30, 653-674.

Furstenberg, F. F., Cook, T. D., Eccles, J., and Elder, G. H. (eds.). Managing to Make It. Chicago: University of Chicago Press, 1999.

Harwood, R., and others. "Parenting Among Latino Families in the U.S." In M. H. Bornstein (ed.), Handbook of Parenting, Vol. 4: Social Conditions and Applied Parenting. (2nd ed.) Mahwah, N.J.: Erlbaum, 2002.

Hazan, C., and Shaver, P. "Romantic Love Conceptualized as an Attachment Process." Journal of Personality and Social Psychology, 1987, 52, 511-524. 
Jensen, L. A., Arnett, J. J., Feldman, S. S., and Cauffman, E. "The Right to Do Wrong: Lying to Parents Among Adolescents and Emerging Adults." Journal of Youth and Adolescence, 2004, 33, 101.

Kerr, M., and Stattin, H. "What Parents Know, How They Know It, and Several Forms of Adolescent Adjustment: Further Support for a Reinterpretation of Monitoring." Developmental Psychology, 2000, 36, 366-380.

Killen, M., and Wainryb, C. "Independence and Interdependence in Diverse Cultural Contexts." In S. Harkness, C. Raeff, and C. M. Super (eds.), Variability in the Social Construction of the Child. San Francisco: Jossey-Bass, 2000.

Lareau, A. Unequal Childhoods: Class, Race, and Family Life. Berkeley: University of California Press, 2003.

Larson, L. E. "The Influence of Parents and Peers During Adolescence: The Situation Hypothesis Revisited." Journal of Marriage and the Family, 1972, 36, 123-138.

Medora, N. P. "Mate Selection in Contemporary India: Love Marriages Versus Arranged Marriages." In R. R. Hamon and B. B. Ingoldsby (eds.), Mate Selection Across Cultures. Thousand Oaks, Calif.: Sage, 2003.

Mize, J., Russell, A., and Pettit, G. S. "Further Explorations of Family-Peer Connections: The Role of Parenting Practices and Parenting Style in Children's Development of Social Competence." In P. T. Slee and K. Rigsby (eds.), Children's Peer Relations. New York: Routledge, 1998.

Mounts, N. S. "Young Adolescents' Perceptions of Parental Management of Peer Relationships." Journal of Early Adolescence, 2001, 21(1), 92-122.

Mounts, N. S. "Parental Management of Adolescent Peer Relationships in Context: The Role of Parenting Style." Journal of Family Psychology, 2002, 16, 58-69.

Parke, R. D., and Bhavnagri, N. "Parents as Managers of Children's Peer Relationships." In D. Belle (ed.), Children's Social Networks and Social Supports. New York: Wiley, 1989.

Parke, R. D., and O’Neil, R. "Social Relationships Across Contexts: Family-Peer Linkages." In W. A. Collins and B. Laursen (eds.), The Minnesota Symposium on Child Psychology, Vol. 30: Relationships as Developmental Contexts. Mahwah, N.J.: Erlbaum, 1999.

Peshkin, A. The Color of Strangers, the Color of Friends. Chicago: University of Chicago Press, 1991.

Phinney, J. S., Kim-Jo, T., Osorio, S., and Vilhjalmsdottir, P. "Autonomy and Relatedness in Adolescent-Parent Disagreements: Ethnic and Developmental Factors." Journal of Adolescent Research, 2005, 20(1), 8-39.

Rogoff, B. The Cultural Nature of Human Development. New York: Oxford University Press, 2003.

Savin-Williams, R. C., and Berndt, T. J. "Friendship and Peer Relations." In S. S. Feldman and G. R. Elliot (eds.), At the Threshold: The Developing Adolescent. Cambridge, Mass.: Harvard University Press, 1990.

Schofield, J. W. Black and White in School: Trust, Tension, or Tolerance? New York: Praeger, 1982.

Simon, V. A., Bouchey, H. A., and Furman, W. "The Social Construction of Adolescents' Representations of Romantic Relationships." In S. Larose and G. M. Tarabulsy (eds.), Attachment and Development, Vol. 2: Adolescence. Quebec: Presses de l'Université du Quebec, 2000.

Smetana, J. G. "Adolescents' and Parents' Conceptions of Parental Authority." Child Development, 1988, 59, 321-335.

Smetana, J. G. "Middle-Class African American Adolescents' and Parents' Conceptions of Parental Authority and Parenting Practices: A Longitudinal Investigation." Child Development, 2000, 71, 1672-1686.

Tilton-Weaver, L. C., and Galambos, N. L. "Adolescents' Characteristics and Parents' Beliefs as Predictors of Parents' Peer Management Behaviors." Journal of Research on Adolescence, 2003, 13, 269-300. 
Trueba, H. T., Jacobs, L., and Kirton, E. Cultural Conflict and Adaptation: The Case of Hmong Children in American Society. New York: Falmer Press, 1990.

Vernberg, E. M., Beery, S. H., Ewell, K. K., and Abwender, D. A. "Parents' Use of Friendship Facilitation Strategies and the Formation of Friendships in Early Adolescence: A Prospective Study." Journal of Family Psychology, 1993, 7, 356-359.

Wade, J. C., and Okesola, O. "Racial Peer Group Selection in African American High School Students." Journal of Multicultural Counseling and Development, 2002, 30, 96-109.

Xiong, Z. B., Detzner, D. F., and Cleveland, M. J. "Southeast Asian Adolescents' Perceptions of Immigrant Parenting Practices." Hmong Studies Journal, 2004-2005, 5, 1-20.

Youniss, J., and Smollar, J. Adolescent Relations with Mothers, Fathers, and Friends. Chicago: University of Chicago Press,1985.

Zhou, M., and Kim, S. "Community Forces, Social Capital, and Educational Achievement: The Case of Supplementary Education in the Chinese and Korean Immigrant Communities." Harvard Educational Review, 1990, 76, 1-29.

B. BRADFORD BROWN, professor of human development and educational psychology at the University of Wisconsin-Madison, examines peer influence and family-peer linkages in adolescence.

NINA S. MOUNTS is associate professor of psychology at Northern Illinois University in DeKalb, Illinois. She studies linkages between parenting and peer relationships during adolescence. 